\title{
Comparison of Treatment with Titanium Elastic Nail Versus AO - Dynamic Compression Plate for Femoral Shaft Fractures in Children
}

\author{
Ejaz Ahmed, ${ }^{1}$ Omer Khalid, ${ }^{2}$ Usman-ul-Haq, ${ }^{3}$ Abu Baker Siddiq ${ }^{4}$
}

\begin{abstract}
Background: Femur fractures are among the commonest pediatric injuries. Until recent past, traction and hip spica were the standard treatment for all femoral shaft fractures which required long duration of hospitalization. The management of femoral shaft fractures in children above the age of six years has evolved more towards operative approaches in the last two decades to minimize the post plaster complications i.e. decrease in incidence of malunion, short hospital stay, better nursing care and early ambulation. Recently, a variety of therapeutic alternatives such as intramedullary nailing and dynamic compression plating have
\end{abstract}

Conflict of Interest: No

Funding Source: No become available to decrease impairment, increase convenience and decrease cost of care.

Objective: To compare the results of fracture shaft of femur in children (6 to 12 years of age) treated with Titanium Elastic Nail vs. AO - Dynamic Compression Plate fixation.

Methods: This prospective, comparative and interventional study was carried out in the department of orthopedic surgery, PGMI Lahore General Hospital, Lahore. A total of 64 patients were enrolled in this study and randomly divided into 2 groups of 32 patients each. In Group-A patients were treated with Titanium Elastic Nail and in Group - B patients were treated with AO - Dynamic Compression Plate fixation. Sample selection was done by using a pre-defined inclusion and exclusion criteria. Variables of interest were duration of operation, Infection, Limb Length discrepancy, Angulation, Time of union and implant failure. Patients were followed up from 2 nd week till 24th week respectively. SPSS was used for data entry and analysis.

Results: Age range of patients was $6-12$ years. Male patients were 51 and 13 patients were female. Eleven patients had Proximal 1/3, 45 mid shaft fracture and 8 distal 1/3 fracture. Mean operative time for DCP was 53.28 minutes and for elastic intramedullary nailing was 29.91 minutes. None of the patients in both treatment groups had limb length discrepancy. Infection and implant failure rate were the same in both treatment groups. Union was rapid till 8th week in GroupA patients after 8th week both treatment groups had equal union rate.

Conclusion: Union was achieved in all cases in both groups. Angulation, Infection and implant failure was 
not seen in any of the patients in both treatment groups. An earlier union of bone was earlier in Group-A (Elastic Intramedullay Nail) patients as compared to Group-B (DCP).

Key Words: AO - DCP, Titanium Elastic Nail, Pediatric Mid Shaft Femur, Infection, Union.

\section{Introduction}

In children the leading cause of morbidity and mortality is trauma (Cusick et al., 2005). After the first year of life in children it accounts for 50\% of mortality and fractures are the most adverse event in their life ${ }^{1}$ (Tandom et al., 2007). ${ }^{1,2}$ Long bone fractures are a frequent cause of morbidity in such cases. Femoral shaft fractures account for $1.6 \%$ of all pediatric fractures (Carvalho Filho et al., 2005). ${ }^{2,3}$ Majority recover uneventfully when consensus guidelines are followed. Children spend most of their time at school or the home. Common mechanisms of injury are fall, sports injuries, traffic accidents, child abuse, and pathological fractures (Lee et al., 2007, Bridgman and Wilson, 2004). ${ }^{4,5}$ Assessment of environmental factors on etiology of fractures in children can be done by the fact that $47 \%$ of fractures occur at home, $13 \%$ in road traffic accidents. ${ }^{2}$ Twenty one percent at school, $17 \%$ during play and $2 \%$ under other circumstances (Tandom et al., 2007). ${ }^{2}$

Treatment option can be considered on the basis of age of the patient i.e. for age up to 5 years conservative management, and surgery for patients above 12 years of age. Current publications show equivocal results with both methods. There is little consensus in an age group of children between 6 years and 12 years of age (Saikia et al., 2007). ${ }^{6}$ Surface implants seem safer because they are less likely to injure epiphyseal growth plates as compared to intra medullary devices. Nails are avoided in children because of the likelihood of greater trochanteric or distal femoral epiphysis. Titanium elastic nails are gaining popularity as the treatment for femoral shaft fractures in 6-12 years of age. They preserve the fracture hematoma as well. Recent publications have suggested that intra medullary titanium elastic nails achieve an earlier union than a plate. This study aimed to compare the results of treatment of femur fracture in children treated with retrograde intramedullary Titanium Elastic Nail and AO plate fixation.

\section{Methodology}

The primary aim of this prospective, interventional and comparative study was to compare the results of fracture shaft of femur in children of 6 to 12 years of age treated with Titanium Elastic Nail vs. AO - Dynamic Compression Plate. It was carried out in the Department of Orthopaedic surgery, PGMI Lahore General Hospital, Lahore in partial fulfillment of MS Orth by an author (EA). It was a prospective study where each case was followed for 6 month following intervention.

Non-probability convenient sampling technique was used to include patients coming to out-patients or emergency. The 64 patients received during the study period with fracture shaft of femur were divided in to two groups i.e. group A and group B by simple randomization (segregation into two groups as they presented one by one). Group A was treated with "Titanium Elastic Nail" and Group B was treated with "AO Dynamic Compression Plate". Femoral shaft fracture, close and Gustilo open type I in children aged between 6-12 years without gender bais were included. Open fractures beyond Gustilo type I, Pathological fractures, Fracture older than 2 weeks and Segmental fracture were all excluded. After surgery follow up was done on fortnightly basis for 2 months and then after every 4 week for 4 months by same observer(EA) and on the following parameters: operation time, minutes (skin to skin closure), Infection, Limb Length discrepancy: In centimeters from anterior superior iliac spine to medial malleolus, Angulations: in antero-posterior and lateral $\mathrm{x}$-rays, Time of union in weeks, bridging callus uniting at least three cortices in biplane $\mathrm{x}$-rays, Implant failure breakage of implant before complete union.

Group - A: During surgery two flexible retrograde (preserving the distal femoral epiphysis) intramedullary nails that range in diameter from 2 to $4 \mathrm{~mm}$ were used (Saam M et al, 2007). Diameter of rods was measured by measuring width of medullary cavity at the narrowest point in both the anteroposterior and lateral view on $\mathrm{X}$-rays or under image intensifier and this number was divided by 2 .

Group - B was operated using AO 4.5 - mm compression plate with cortical / cancellous screws or both.

At the conclusion of study period the data recorded were entered and analyzed through statistical package for social sciences (SPSS) Version 19.0. Frequency and percentage were calculated to represent the qualitative variables like gender, infection and implant 
failure. Mean and standard deviations was calculated for quantitative variables like age, operation time, time of union, angulation and limb length discrepancy. Pearson's Chi-Square test was applied to compare qualitative variables and student's T- test was used to compare quantitative variables between both groups. Pvalue of $\leq 0.05$ was considered to be significant.

\section{Results}

Mean age of patients in Group - A was $8.75 \pm 1.77$ and in Group - B mean age was $8.87 \pm 1.74$ years respectively. Minimum age of patients in both treatment groups was 6 and maximum age was 12 years. Gender distribution in Group-A shows that there were 25 male and 7 female patients in this group. Whereas in Group - B 26 patients were male and 6 patients were females. Mean operative time of both treatment group was $29.91 \pm 4.61$ and $53.28 \pm 6.86$ minutes respectively. According to $\mathrm{p}$-value mean operative time for both treatment group was statistically different. Operative time was higher for Group - B patients.
Table 1: Descriptive Statistics for Age in Treatment Groups.

\begin{tabular}{|l|c|c|c|}
\hline \multirow{2}{*}{} & \multicolumn{2}{|c|}{ Treatment Group } & \multirow{2}{*}{ Total } \\
\cline { 2 - 3 } & Group - A & Group - B & \\
\hline Number & 32 & 32 & 64 \\
\hline Mean & 8.75 & 8.87 & 8.81 \\
\hline SD & 1.77 & 1.74 & 1.74 \\
\hline Minimum age & 6 & 6 & 6 \\
\hline Maximum age & 12 & 12 & 12 \\
\hline
\end{tabular}

Group $-\mathrm{A}=$ Titanium Elastic Nail

Group $-\mathrm{B}=\mathrm{AO}-$ Dynamic Compression Plate

At $4^{\text {th }}$ and $6^{\text {th }}$ week only 1 patient in Group - A suffered from infection. Implant failure was not observed in any of the patients in both treatment groups. At $2^{\text {nd }}$ week in Group - A 21 Patients had Grade - 4 and 11 patients had Grade-5 union where as in Group - B all patients had Grade -5 union. P-value shows significant union in Group-A patients. At $4^{\text {th }}, 6^{\text {th }}$ and $8^{\text {th }}$

Table 2: Descriptive Statistics for Angulation in Treatment Groups from $2^{\text {nd }}$ Week till $24^{\text {th }}$ Week Follow-up.

\begin{tabular}{|c|c|c|c|c|c|c|c|c|c|}
\hline & \multirow{2}{*}{ Group } & \multirow{2}{*}{$\mathrm{N}$} & \multicolumn{6}{|c|}{ Angulation } & \multirow{2}{*}{ p-value } \\
\hline & & & $0^{\circ}$ & $1^{\circ}$ & $3^{\circ}$ & $5^{\circ}$ & $6^{\circ}$ & $8^{\circ}$ & \\
\hline \multirow{3}{*}{ Angulation at 2 weeks } & Group - A & 32 & 27 & 0 & 3 & 1 & 0 & 1 & \multirow{3}{*}{0.143} \\
\hline & Group - B & 32 & 32 & 0 & 0 & 0 & 0 & 0 & \\
\hline & Total & 64 & 59 & 0 & 3 & 1 & 0 & 1 & \\
\hline \multirow{3}{*}{ Angulation at 4 weeks } & Group - A & 32 & 27 & 0 & 3 & 1 & 0 & 1 & \multirow{3}{*}{0.143} \\
\hline & Group - B & 32 & 32 & 0 & 0 & 0 & 0 & 0 & \\
\hline & Total & 64 & 59 & 0 & 3 & 1 & 0 & 1 & \\
\hline \multirow{3}{*}{ Angulation at 6 weeks } & Group - A & 32 & 27 & 3 & 0 & 1 & 1 & 0 & \multirow{3}{*}{0.143} \\
\hline & Group - B & 32 & 32 & 0 & 0 & 0 & 0 & 0 & \\
\hline & Total & 64 & 59 & 3 & 0 & 1 & 0 & 1 & \\
\hline \multirow{3}{*}{ Angulation at 8 weeks } & Group - A & 32 & 30 & 0 & 1 & 0 & 1 & 0 & \multirow{3}{*}{0.356} \\
\hline & Group - B & 32 & 32 & 0 & 0 & 0 & 0 & 0 & \\
\hline & Total & 64 & 62 & 0 & 1 & 0 & 1 & 0 & \\
\hline \multirow{3}{*}{ Angulatio at 12 weeks } & Group - A & 32 & 31 & 0 & 0 & 0 & 1 & 0 & \multirow{3}{*}{0.313} \\
\hline & Group - B & 32 & 32 & 0 & 0 & 0 & 0 & 0 & \\
\hline & Total & 64 & 63 & 0 & 0 & 0 & 1 & 0 & \\
\hline
\end{tabular}




\begin{tabular}{|c|c|c|c|c|c|c|c|c|c|}
\hline \multirow{3}{*}{ Angulation at 16 weeks } & Group - A & 32 & 31 & 0 & 0 & 0 & 1 & 0 & \multirow{3}{*}{0.313} \\
\hline & Group - B & 32 & 32 & 0 & 0 & 0 & 0 & 0 & \\
\hline & Total & 64 & 63 & 0 & 0 & 0 & 1 & 0 & \\
\hline \multirow{3}{*}{ Angulation at 20 weeks } & Group - A & 32 & 31 & 0 & 0 & 0 & 1 & 0 & \multirow{3}{*}{0.313} \\
\hline & Group - B & 32 & 32 & 0 & 0 & 0 & 0 & 0 & \\
\hline & Total & 64 & 63 & 0 & 0 & 0 & 1 & 0 & \\
\hline \multirow{3}{*}{ Angulation at 24 weeks } & Group - A & 32 & 31 & 0 & 0 & 0 & 1 & 0 & \multirow{3}{*}{0.313} \\
\hline & Group - B & 32 & 32 & 0 & 0 & 0 & 0 & 0 & \\
\hline & Total & 64 & 31 & 0 & 0 & 0 & 1 & 0 & \\
\hline
\end{tabular}

Group $-\mathrm{A}=$ Titanium Elastic Nail

Group $-\mathrm{B}=\mathrm{AO}-$ Dynamic Compression Plate

week patients had significant union in Group - A. Whereas from $12^{\text {th }}$ week till 24 th week follow-up fracture union was same in both treatment groups.

\section{Discussion}

In 1977 in Nancy, France ESIN (elastic stable intramedullary nailing) was used to treat patients with long bone fracture due to rickets. A series of key publications followed, mostly in French, culminating in the publication in 1988 of Métaizeau's book on the technique and on the pediatric femoral shaft fractures stabilization the first major publication in an English language publication ${ }^{7}$. This method has a number of advantages: it is easy to carry out, has low risk of infection; does not interfere with the fracture hematoma preserving it; does not produce any physeal insult. The disadvantages of this system are also well known e.g. need of an X-rays imaging device during surgery, discomfort when moving the knee due to protrusion of the elastic nails. In this study mean age of patients was 8.81 years (range $6-12$ ). Gender distribution shows $79.9 \%$ male and $20.1 \%$ female patients. Four patients had open type-I fracture i.e. three in group A and one in group B while the remaining 60 patients had close fracture i.e 29 in group A and 31 in group B.. During follow up only one patient suffered from superficial infection in Group - A, it was treated adequately by antibiotics and antiseptic dressings. None of the patients in both treatment groups had implant failure during 6 months of study. Union was statistically earlier in Group - A from $2^{\text {nd }}$ week till $8^{\text {th }}$ week. After that union was statistically same in both treatment groups.
Commonly used methods in clinical practice are skin or skeletal traction, casting, external fixation, open reduction and internal fixation with plating and close reduction and internal fixation under image intensifier with the locked or flexible intramedullary nailing.(Lee et al., 2007, Cusick et al., 2005). ${ }^{1,4}$ The disadvantage of DCP includes surgical incision to insert/remove the plates, plate breakage femoral overgrowth, risk of infection, and re-facture after removal. Implant failure or Plate breakage needs reoperation, although rare, has been reported. Common complications of femoral shaft fractures in children are Limb Length Discrepancy, Malunion/angulations, Rotational deformity, Infection, Delayed Union and Non Union Different treatment methods are being used to treat these patients depending upon type, site and age of child (Moroz et al., 2006). ${ }^{8}$ Majority of the patients (45 patients) in this study had mid shaft fractures while 11 patients had proximal $1 / 3$ and 8 patients had fracture of the distal 1/3 of femoral shaft. None of the patients in both treatment groups had leg length discrepancy. No significant difference was seen in terms of angulation in both treatment groups. Kalra in his study treated 16 children ( 14 boys and 2 girls) with Titanium elastic nails for femoral diaphyseal fractures. The mean age was 12.5 years (range $7-16$ years). ${ }^{9}$ Radiological union of all fractures was achieved at a mean of 7.5 weeks (range $5-10$ weeks). They found limb length discrepancy of $1.0 \mathrm{~cm}$ in one child and $10^{\circ}$ of internal rotational in another. Despite of these minor rotational deformities Titanium elastic nailing seems to be a safe and effective method for the management of pediatric femoral shaft fractures (Kalra et al., 2011). ${ }^{9}$

In our study the union was rapid in Group A from 
$2^{\text {nd }}$ to $8^{\text {th }}$ week after that union was statistically same in both treatment groups. Mean union time in Group A was 6 weeks and Group B was 11 weeks. Plating being an invasive procedure seems more likely hypothetically to result in delay in achieving union in such cases. Our small scale study refutes such observations. There is need to study the matter further in large scale studies.

\section{Conclusion}

Based on the results of this study it is concluded that both two groups show promising results but keeping in mind the amount of trauma by open plating it is observed that closed intra-medullary titanium elastic nailing is better method of operative treatment for pediatric femoral diaphyseal fractures.

\section{References}

1. Cusick, L., Thompson, N., Taylor, T. and Cowie, G. Paediatric femoral fractures - the Royal Belfast Hospital for Sick Children experience. The Ulster medical journal, 2005; Vol. 74: p. 98.

2. Tandom, T., Shaik, M. and Modi, N. Paediatric trauma epidemiology in an urban scenario in India. Journal of Orthopaedic Surgery, 2007; Vol. 15, No. 1: pp. 42-44.

3. Carvalho Filho, G., Chueire, A. G., Ignácio, H., Amaral, A. R. C. D., Catelan, G. M. and Júnior, C. External fixation in femur fractures in children. Acta Ortopédica Brasileira, 2005; Vol. 13: pp. 35-37.

4. Lee, Y. H., Lim, K. B., Gao, G., Mahadev, A., Lam, K., Tan, S. and Lee, E. Traction and spica casting for closed femoral shaft fractures in children. Journal of Orthopaedic Surgery, 2007; Vol. 15, No. 1: pp. 37-40.

5. Bridgman, S. and Wilson, R. Epidemiology of femoral fractures in children in the West Midlands region of England 1991 to 2001. Journal of Bone and Joint Surgery - B, Vol. 86, pp. 1152-1157 Metaizeau, J.-P. 2004. Stable elastic intramedullary nailing for fractures of the femur in children. Journal of Bone and Joint Surgery, British Volume, 2004; Vol. 86: pp. 954-957.

6. Saikia, K., Bhuyan, S., Bhattacharya, T. and Saikia, S. Titanium elastic nailing in femoral diaphyseal fractures of children in $6-16$ years of age. Indian journal of orthopaedics, 2007; Vol. 41: p. 381.

7. Metaizeau, J.-P., Lascombes, P., Lemelle, J.-L., Finlayson, D. and Prevot, J. Reduction and fixation of displaced radial neck fractures by closed intramedullary pinning. Journal of Pediatric Orthopaedics, 1993; Vol. 13: pp. 355-360.

8. Moroz, L., Launay, F., Kocher, M., Newton, P., Frick, S., Sponseller, P. and Flynn, J. Titanium elastic nailing of fractures of the femur in children predictors of complications and poor outcome. Journal of Bone \& Joint Surgery, British Volume, 2006; Vol. 88: pp. 1361-1366.

9. Kalra, M., Mahmood, A. and Patralekh, M. K.. Treatment of pediatric femoral shaft fractures with titanium elastic nails - our experience. Journal of Clinical Orthopaedics and Trauma, 2011; Vol. 2: pp. 46-50. 